\title{
Study on Sludge Expansion During Treatment of Salad Oil Manufacturing Wastewater by Yeast
}

\section{S. Zheng , M. Yang , W. Lv \& F. Liu}

To cite this article: S. Zheng , M. Yang , W. Lv \& F. Liu (2001) Study on Sludge Expansion During Treatment of Salad Oil Manufacturing Wastewater by Yeast, Environmental Technology, 22:5, 533-542, DOI: 10.1080/09593332208618257

To link to this article: http://dx.doi.org/10.1080/09593332208618257

\section{曲 Published online: 11 May 2010.}

Submit your article to this journal $\lceil\pi$

山 Article views: 32

Q View related articles $\square$

7 Citing articles: 6 View citing articles ๘ 


\title{
STUDY ON SLUDGE EXPANSION DURING TREATMENT OF SALAD OIL MANUFACTURING WASTEWATER BY YEAST
}

\author{
State Key Laboratory of Environmental Aquatic Chemistry, Research Center for Eco-Environmental Sciences, \\ Chinese Academy of Sciences, P.O. Box 2871, Beijing 100085, China
}

(Received 4 October, 2000; Accepted 8 December 2000)

\begin{abstract}
Five yeast strains, namely Rhodotorula rubra, Candida tropicalis, Candida utilis, Candida boidinii, Trichosporon cutaneum, were isolated from soil spots of a salad oil factory, and applied for continuous treatment of salad oil manufacturing wastewater. The oil and COD removal performance of the mixed cultures were comparable to the results other researchers obtained. Sludge expansion, accompanied with sludge morphology change from pseudomycelia to true mycelia, occurred during continuous treatment of wastewater. The true mycelia dominated sludge had a much higher water content and SVI value than that of the yeast pure cultures, although the two kinds of sludge had similar oil removal performance. A mold, Geotrichum candidum, was isolated from the expanded sludge, and was suspected to be a reason for sludge expansion. Addition of $0.3 \%$ sodium propionate into batch cultures degraded SVI value from around 100 to 60 . In a continuous running, addition of $10 \mathrm{mg} \mathrm{l}^{-1}$ sodium hypochlorite decreased SVI value from over 200 to below 100 . The yeast activity, however, was weakened to a large extent at the same time.
\end{abstract}

Keywords:

Yeast; wastewater treatment; yeast treatment process; salad oil wastewater; sludge expansion; mycelia; pseudomycelia.

\section{INTRODUCTION}

The production of salad oil has increased significantly in China over the past decades. Wastewater discharged during salad oil production contains a high concentration of oil, and could not be effectively treated directly with the conventional aerobic or anaerobic biological processes $[1,2]$. The normal practice has been to remove most of the oil with a physico-chemical method before biological treatment. This practice, however, consumes a lot of acids and alkali compounds because the $\mathrm{pH}$ must be adjusted to as low as 2 in order to remove most of the fatty acids. Another problem is that the oily sludge is very difficult to handle and reutilize [3].

Chigusa et al. [4-8] has developed a novel process utilizing yeast to treat high strength organic wastewater under aerobic conditions. The COD loading rate of the process could be 8 to 10 times higher than that of the conventional activated sludge method. Another interesting characteristic is that it could be used for treating oil-rich wastewater with high efficiency [9]. A hexane extract removal as high as $99 \%$ could be obtained for treating wastewaters containing of concentrations higher than $10000 \mathrm{mg} \mathrm{l}^{-1}$, A succeeding activated sludge process could be used to remove the residual COD, Compared with the conventional aerobic or anaerobic biological processes, however, studies on the yeast wastewater treatment process have been very limited. Although the good settling property of yeast was considered to be related with formation of pseudomycelia [9], many other aspects of the yeast process, like stability of the yeast system, have been minimal.

In this study, the stability of the yeast treatment system was investigated on salad oil wastewater. After the phenomenon of sludge expansion was observed, efforts were devoted to clarification of the causes. The possibility of controlling sludge expansion was also investigated.

\section{MATERIALS AND METHODS}

Enrichment, isolation, and identification

An enrichment and isolation program is shown in Figure 1. The field soil was collected from several spots contaminated with salad oil wastewater in a salad oil factory, 
Field soil contaminated with wastewater

$20 \mathrm{ml} / 150 \mathrm{ml}$ of wastewater in a $500 \mathrm{ml}$ Erlenmeyer flask

Fill-and-draw shaking culture $\left(25^{\circ} \mathrm{C}, \mathrm{pH} 5-5.5,20\right.$ days)

$5 \mathrm{ml} / 150 \mathrm{ml}$ of YPD medium in a $500 \mathrm{ml}$ Erlenıneyer flask

Shaking culture $\left(25^{\circ} \mathrm{C} .2\right.$ days $)$

$0.2 \mathrm{ml}$ of YPD medium

Plate culture $\left(25^{\circ} \mathrm{C}, 2\right.$ days $)$

Stock culture

Figure 1. Procedure for enrichment and isolation of yeast.

and incubated in $500 \mathrm{ml}$ Erlenmeyer flasks containing $150 \mathrm{ml}$ of the salad oil manufacturing wastewater at 170 strokes min $^{-1}$ on a reciprocal shaker. The $\mathrm{pH}$ of the solution was adjusted to a range between 5.0 and 5.5, and the temperature was controlled at $25^{\circ} \mathrm{C}$. Sixty units per milliliter penicillin and $0.25 \%$ sodium propionate were added to the solution for preventing the growth of bacteria and mold, respectively. The cultivation was conducted in a fill-and-draw mode for $\mathbf{2 0}$ days, and the solution was changed once a day. After culturing in YPD medium (Yeast Extract-Peptone-Dextrose medium, Table 1) for 2 days, yeast strains were transferred to YPD agar plates for isolation.

Isolation of the expanded sludge occurred during continuous running using a similar procedure. Microorganisms were identified based on morphological and biochemical characteristics described by Kreger-van Rij [10].
Wastewater characterization

Wastewater was taken from the same factory where the soil samples were taken. Wastewater characteristics are shown in Table 2. It is apparent that the oil concentration (petroleum ether extract, PEE) was very high, and constituted the main part of COD. The concentration of total phosphorus (TP) was relatively high perhaps due to the existence of phosphatide. The total nitrogen (TN), however, was very low. The COD: $N$ was 873: 1, much higher than that of a similar wastewater (COD: $N$ of 92: 1) used by Chigusa et al [9].

Bench scale treatment system

A lucite aeration tank (effective volume of 12 l) equipped with a 101 cylindrical sedimentation column

Table 1. Composition of YPD agar medium.

\begin{tabular}{llllll}
\hline Items & Yeast extract & Peptone & Dextrose & Agar & Tap water \\
\hline Dose & $5 \mathrm{~g}$ & $10 \mathrm{~g}$ & $20 \mathrm{~g}$ & $20 \mathrm{~g}$ & $1000 \mathrm{ml}$ \\
\hline
\end{tabular}

Table 2. Characteristics of salad oil manufacturing wastewater.

\begin{tabular}{lllr}
\hline \multicolumn{3}{l}{ Items and concentrations } & \multicolumn{3}{l}{ Items and concentrations } \\
\hline $\mathrm{COD} / \mathrm{mg} \mathrm{l}^{-1}$ & 134380 & $\mathrm{TP} / \mathrm{mg} \mathrm{l}^{-1}$ & 6495 \\
$\mathrm{PEE} / \mathrm{mg} \mathrm{l}^{1}$ & 89687 & Protein $/ \mathrm{mg} \mathrm{l}^{-1}$ & 445 \\
$\mathrm{TOC} / \mathrm{mg} \mathrm{l}^{-1}$ & 39000 & Carbohydrate $/ \mathrm{mg} \mathrm{l}^{-1}$ & 9368 \\
$\mathrm{MLSS} / \mathrm{mg} \mathrm{l}^{-1}$ & 9600 & $\mathrm{pH}$ & $8.5 \AA-9.0$ \\
$\mathrm{TN} / \mathrm{mg} \mathrm{l}^{-1}$ & 154 & & \\
\hline
\end{tabular}


constituted the yeast treatment system. The $\mathrm{pH}$ in the aeration tank was automatically controlled at a given value with $\mathrm{H}_{2} \mathrm{SO}_{4}$ and a non-paper recorder was used to record $\mathrm{pH}$ and temperature in aeration tank. Diluted wastewater was pumped into the aeration tank at a given rate, and sludge from the sedimentation tank was returned to the aeration tank continuously with a peristaltic pump. Its schematic diagram is shown in Figure 2.

Seed sludge cultivation

All of the strains acquired through the above enrichment and isolation procedure were inoculated to a CSTR (continuously stirred tank reactor, effective volume of $30 \mathrm{l}$ ), and were cultivated with diluted wastewater (25,000 $\mathrm{mg} \mathrm{l}^{-1}$ COD). The CSTR seed tank was aerated by an $801 \mathrm{~min}^{-1}$ air pump and the $\mathrm{pH}$ was maintained at $\mathrm{pH}$ 5-6 with $\mathrm{H}_{2} \mathrm{SO}_{4} .15$ liters of supernatant were replaced once a day with diluted wastewater into which 11 raw wastewater, $0.25 \%$ sodium propionate, $0.4 \%$ ammonium sulfate and $0.04 \%$ $\mathrm{KH}_{2} \mathrm{PO}_{4}$ were added. The seed sludge was used for startup of the continuous bench scale test.

Continuous operation

The yeast treatment system was inoculated with the seed sludge, and 10 hours aeration was conducted before the system was continuously fed with diluted salad oil wastewater. Table 3 shows operation conditions. During running, excess sludge was not withdrawn since the sludge grew very slowly as a result of nitrogen shortage in the influent wastewater.

Comparison of true mycelia dominated sludge and pure cultures

Highly expanded sludge with well-developed true mycelia from the aeration tank and the axenic cultures of isolated yeasts in YPD culture were respectively centrifuged at $5000 \mathrm{rpm}$ for $10 \mathrm{~min}$ and then washed with tap water for three times. After that, they were respectively inoculated in $1 \mathrm{I}$ diluted wastewater whose $\mathrm{pH}$ was adjusted to 5 . The solutions were stirred at $175 \mathrm{rpm}$, and aerated with an air feeding rate of $21 \mathrm{~min}^{-1}$. Concentrations of MLSS and PEE were measured every 12 hours.

Control of sludge expansion by adding sodium propionate

Sludge containing well-developed true mycelia was cultured again in the seed sludge tank in fill-and-draw mode. The operation conditions were almost same as those used for seed sludge cultivation except that $0.3 \%$ sodium propionate was used in this test. Every day only SVI and MLSS were examined.

Control of sludge expansion by adding sodium hypochlorite

Sodium hypochlorite was continuously added into the aeration tank for the purpose of controlling sludge expansion after well-developed true mycelia were observed. The dose of effective chlorine was 5 to $10 \mathrm{mg} \mathrm{l}^{-1}$, and the other operation conditions were same as the above continuous test.

\section{Analytical methods}

The dissolved oxygen concentration (DO) was measured with a portable meter (DO-11P, TOA Electronics Ltd., Japan), COD was measured using the rapid COD analyzer (CTL-12, Huatong Ltd., China). The COD of effluent was determined after samples were filtered with qualitative filter paper so as to remove microorganisms. Other analyses were carried out in accordance with standard methods [11]. The filter paper for MLSS measurement was rinsed with petroleum ether 3 times to remove residual oil

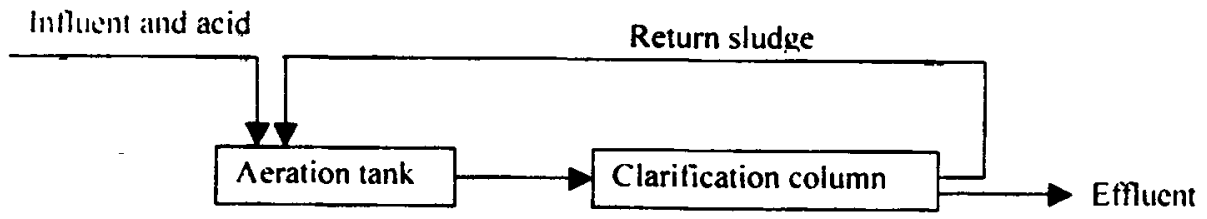

Figure 2. Schematic diagram of the bench scale yeast treatment system.

Table 3. Operation conditions of laboratory-scale test.

\begin{tabular}{llllllll}
\hline $\begin{array}{l}\text { Feeding } \\
\text { rate } \\
\left(1 \mathrm{~d}^{-1}\right)\end{array}$ & $\begin{array}{l}\text { Influent } \\
\text { PEE } \\
\left(\mathrm{mg} \mathrm{l}^{-1}\right)\end{array}$ & $\begin{array}{l}\text { Influent } \\
\text { COD } \\
\left(\mathrm{mg} \mathrm{l}^{-1}\right)\end{array}$ & SS & $\begin{array}{l}\text { PEE } \\
\text { Load } \\
\left(\mathrm{mg} \mathrm{l}^{-1}\right)\end{array}$ & $\begin{array}{l}\text { COD } \\
\text { Load } \\
\left(\mathrm{kg} \mathrm{kg}^{-1} \mathrm{~d}^{-1}\right)\end{array}$ & $\begin{array}{l}\text { pH } \\
\left(\mathrm{kg} \mathrm{k}^{-1} \mathrm{~d}^{-1}\right)\end{array}$ & $\begin{array}{l}\text { Temp } \\
\left({ }^{\circ} \mathrm{C}\right)\end{array}$ \\
\hline 16.5 & $1400-2200$ & $4100-7400$ & $3000-8000$ & $0.2-0.9$ & $1.2-3.2$ & 5.0 & $25-30$ \\
\hline
\end{tabular}


after filtration. Oil content was determined by separation with petroleum ether.

\section{RESULTS AND DISCUSSION}

Results of bench scale treatment

Variations of some important parameters are shown in Figure 3 and 4, respectively. It is clear that an oil removal over
$97 \%$ and COD removal over $93 \%$ were acquired for the first 10 days in spite of variation of sludge load from 1.0 to $3.5 \mathrm{~kg}$ COD $\mathrm{kg} \mathrm{MLSS}^{-1} \mathrm{~d}^{-1}$ (or volumetric load from 5 to $14 \mathrm{~kg}$ COD $\mathrm{m}^{-3} \mathrm{~d}^{-1}$ ). The performance of the yeast treatment system was comparable to that reported by Chigusa et al [9]. The SVI of sludge improved significantly after startup, and reached 50 from the $5^{\text {th }}$ day. Microscope observation results indicated that the dominated morphology of yeast changed gradually from single cells to well-developed pseudomycelia (Plate a-b).

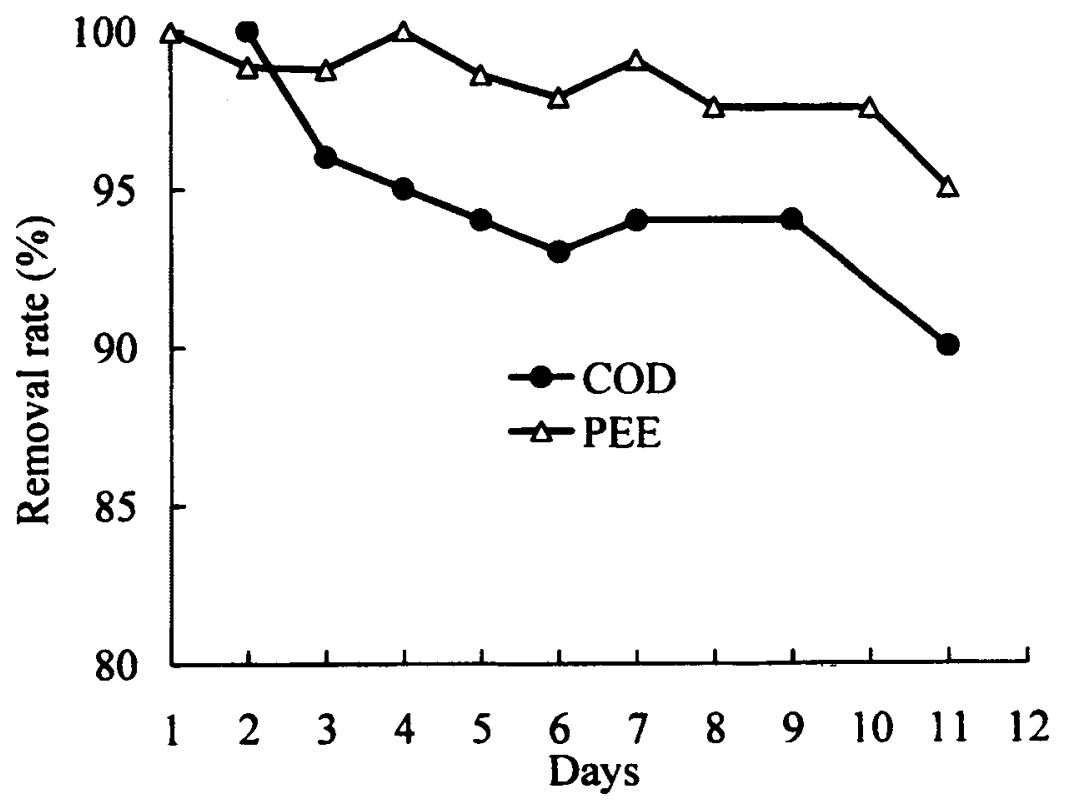

Figure 3. PEE and COD removal performance during 12 days in continuous running.

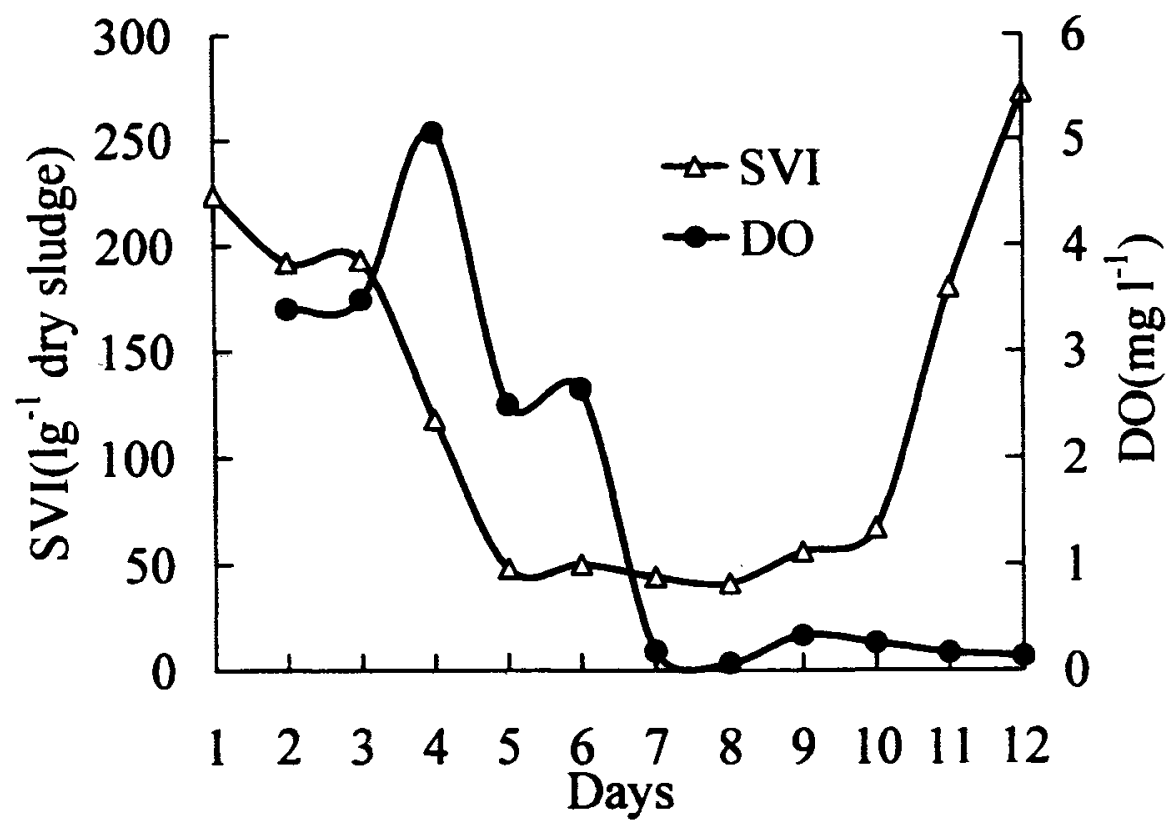

Figure 4. Variation of SVI and DO during 12 days in continuous running. 


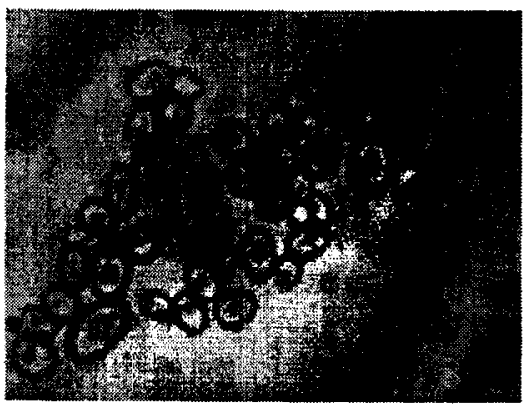

Plate a. Single-cell Yeast (x640).

The SVI, however, increased suddenly from the $11^{\text {th }}$ day, accompanied with the second change of morphological characteristics of sludge. The sharp ascension of SVI values resulted in the heavy deterioration of the settling property of

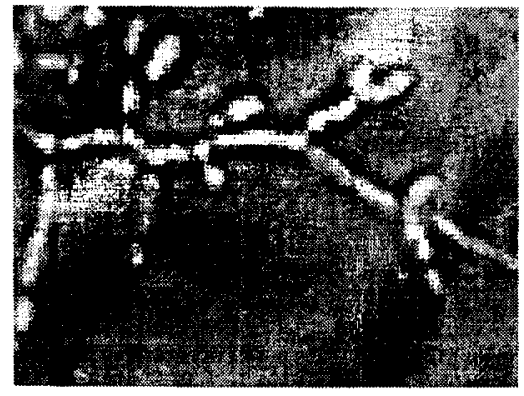

Plate b. Pseudomycelia of yeast $(\times 640)$.

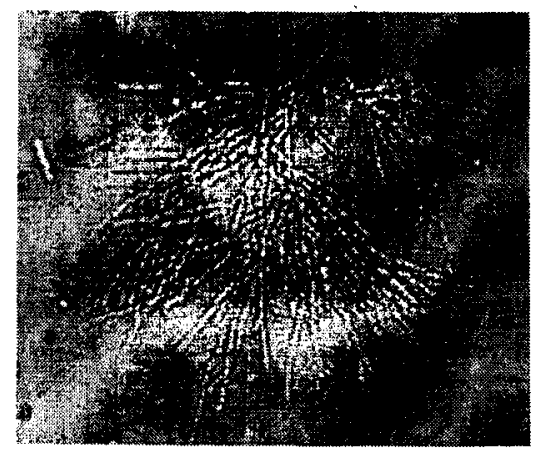

sludge, and the operation had to be stopped. We noticed that the dominated microorganisms changed from the welldeveloped pseudomycelia to true mycelia following the sudden rising of SVI (Plate b-c). It is possible that the increase

Plate c. True mycelia $(\times 640)$.

Plate d. Colonies of true mycelia in agar medium. 
in SVI originated from the change of morphological characteristics of sludge. It was also observed that sludge expansion occurred after $D O$ was kept at a little above zero for several days. The relationship between sludge expansion and lack of DO, however, was uncertain here. The growth of true mycelia in YPD agar medium was shown in Plate d, which suggests that some mold lived alongside the yeasts. It seemed the yeast sludge was somehow contaminated by mold during wastewater treatment. Mold tended to form true mycelia. Some yeast strains, however, could also form true mycelia under certain conditions. So, it was not certain if contamination of mold was the main cause of the failure of the yeast treatment system.

Comparison of true mycelia dominated sludge and pure cultures

The comparison test results and the characteristics of the two kinds of sludge are shown in Figure 5 and Table 4, respectively. It was found that the two kinds of sludge demonstrated similar oil removal performance. In both cases, most of PEE was removed within 24 hours. In the reactor containing true mycelia dominated sludge, however, PEE increased again after further aeration. It was possible that a part of oil absorbed by true mycelia was released again during cell lysis. The most obvious difference between the two kinds of sludge was observed in some physical properties: true mycelia showed a much higher cell growth rate, moisture content, and SVI value. The SVI of true mycelia was too high for practical use.

\section{Enrichment, isolation, and identification}

According to the colony's characteristics of stock cultures, 12 strains of yeasts isolated from enrichment cultures using salad oil manufacturing wastewater were chosen for identification, from which we obtained five yeast strains which belonged to three genera and were labeled as N1-N5 in Table 5-6. The fungus-like strain isolated from true mycelia dominated expanded sludge was marked as N6 in Table 5-6. According to their characteristics in Table 5, the strains were identified as shown in Table 6. It is interesting that most of the strains were different from those reported by Chigusa et al. [9], and the number of yeast strains was less.

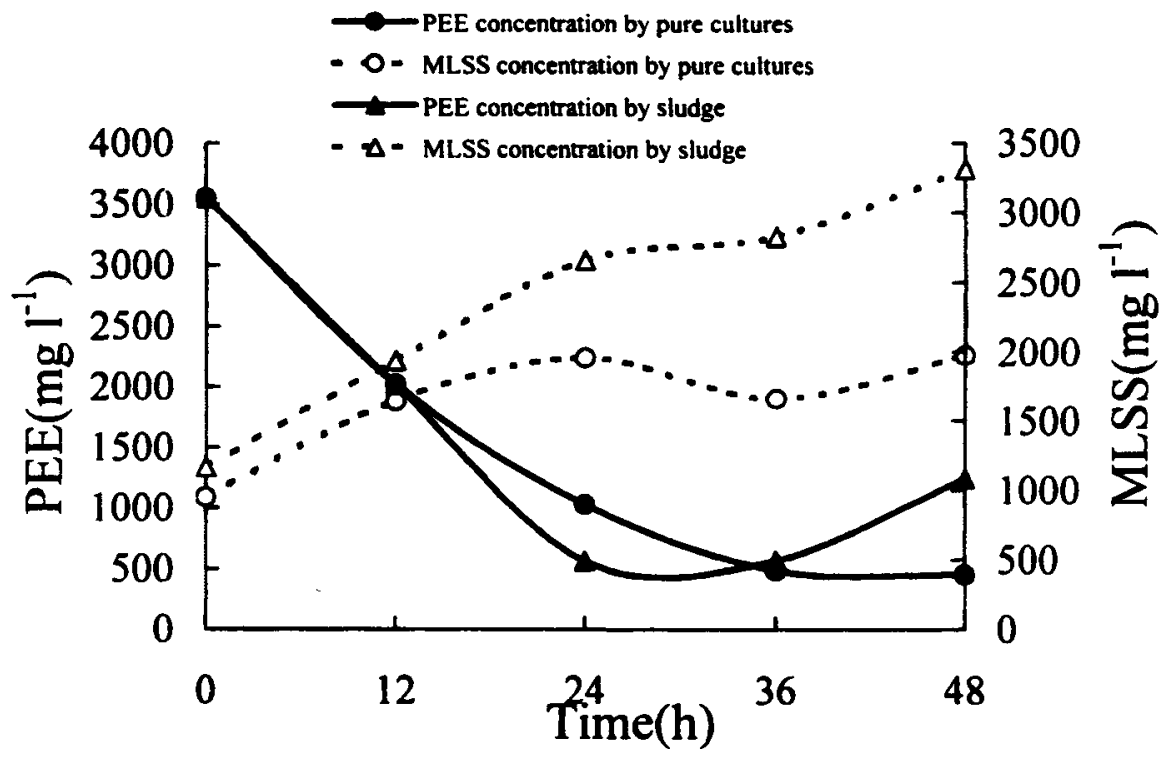

Figure 5, Comparison of true mycelia dominated sludge and yeast pure cultures.

Table 4. Comparison of true mycelia and single-cell yeast.

\begin{tabular}{lll}
\hline Items & Yeast cells & Mycelia \\
\hline Moisture content (\%) & 78.8 & 89.5 \\
SVI & $13-15$ & $301-304$ \\
PEE removal(\%) ir. $24 \mathrm{~h}$ & 71 & 84 \\
PEE removal rate $\mathrm{igg} \mathrm{kg} \mathrm{kLSS} \mathrm{d}^{-1}$ ) in $24 \mathrm{~h}$ & 1.5 & 1.6 \\
\hline
\end{tabular}




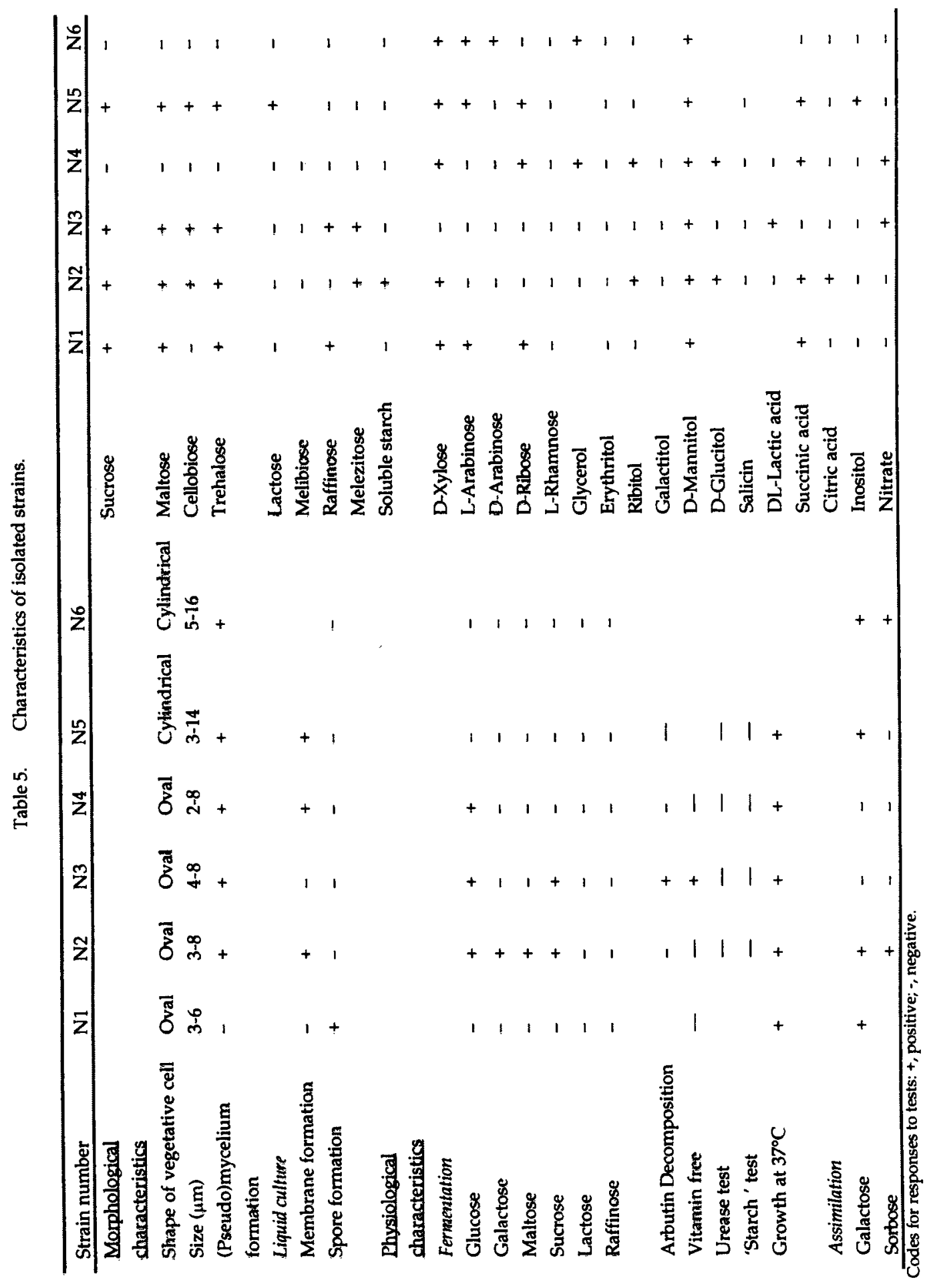


Table 6. Isolated strains.

\begin{tabular}{ll}
\hline No. & Species \\
\hline N1 & Rhodotorula rubra \\
N2 & Candida tropicalis \\
N3 & Candida utilis \\
N4 & Candida boidinii \\
N5 & Trichosporon cutaneum \\
N6 & Geotrichum candidum \\
\hline
\end{tabular}

Among these strains, some yeast strains such as Candida tropicalis and Trichosporon cutaneum form true mycelia in some cases, while Geotrichum candidum absolutely takes the shape of true mycelia. It was possible that Geotrichum candidum played an important role in sludge expansion. However, the possibility of contribution by the two kinds of yeasts could not be excluded as they also have the ability to form true mycelia. On the other hand, sludge expansion could also be related to the treatment conditions and wastewater characteristics. More studies were therefore needed in order to decide the decisive reason for sludge expansion.

Inhibition of molds by sodium propionate in batch cultures

Sodium propionate has been frequently used to repress the growth of molds for screening yeasts. Therefore, sludge expansion could be controlled by adding sodium propionate if Geotrichum candidum, a mold, was the decisive cause. As shown in Figure 6, the SVI value declined from around 100 to 60 or so after expanded sludge was cultured for several days in the presence of sodium propionate. Under the microscope, single cell and pseudomycelia became increasingly predominant at the same time as true mycelia diminished. While the result of this test was not a decisive proof, it is reasonable to estimate that the mold, Geotrichum candidum, possibly caused sludge expansion. While sodium propionate was found to be effective for decreasing SVI, a dose as high as $0.3 \%$ was too high to be practically used.

Control of sludge expansion by adding sodium hypochlorite

Sodium hypochlorite has often been used for depressing sludge expansion of activated sludge. The possibility of using sodium hypochlorite for depressing sludge expansion of yeast sludge was also investigated in this study. The results are shown in Figure 7 and Figure 8. After significant sludge expansion was observed, addition of sodium hypochlorite was started with an effective chlorine dose of $5 \mathrm{mg} \mathrm{l}^{-1}$. The SVI of sludge began to decrease while MLSS in the reactor increased immediately after addition of hypochlorite. Further decrease of SVI, however, was not observed after the SVI reached 150. Then the dose of hypochlorite was increased to $10 \mathrm{mg} \mathrm{l}^{-1}$. The effectiveness of hypochlorite for decreasing SVI was apparent: the SVI declined gradually from 150 to 80 . The addition of hypochlorite, however, has also weakened the activity of yeast sludge and led to the deterioration of oil and COD removals. It was possible that some effective yeast strains were also killed together with the mold.

Hypochlorite was effective for decreasing SVI with a

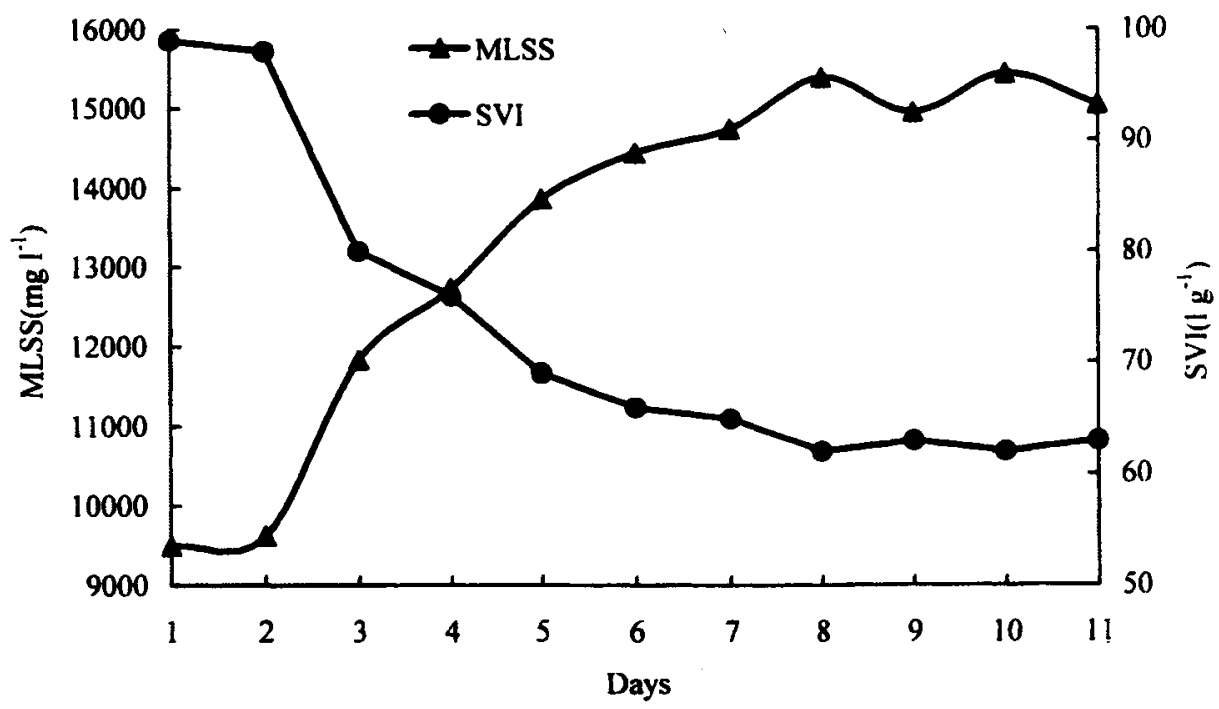

Figure 6. Effect of sodium propionate on SVI value in batch cultures. 


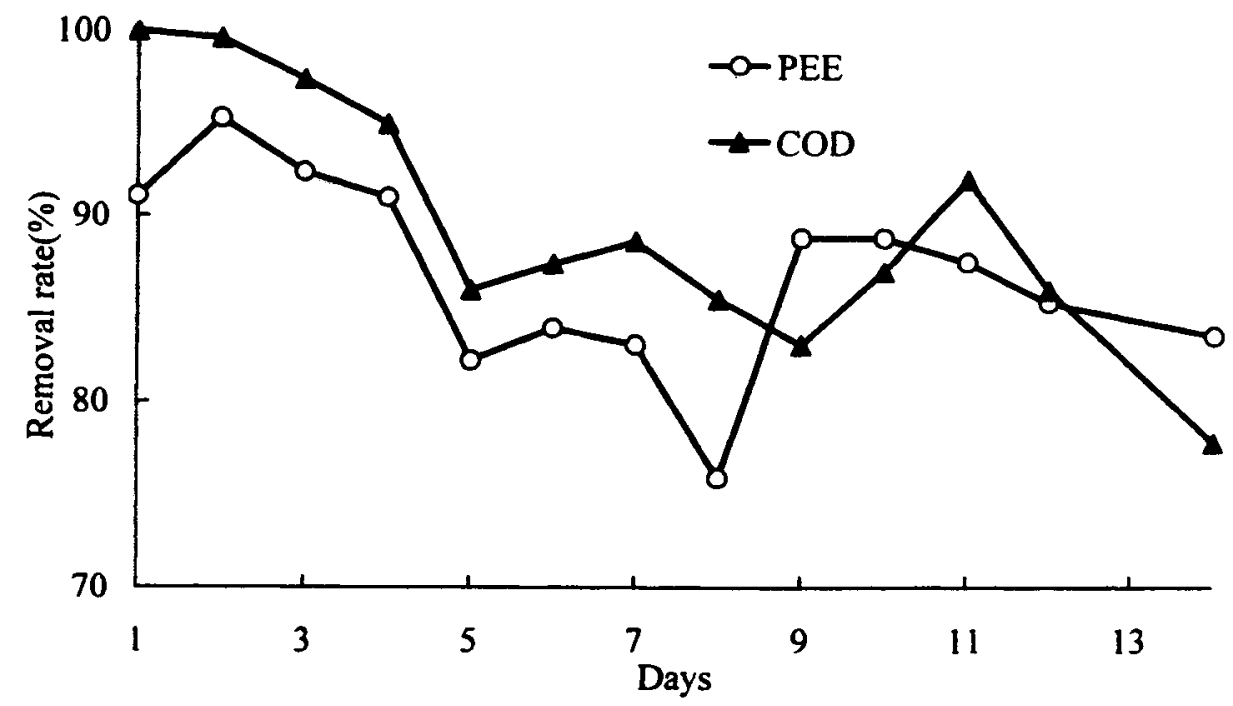

Figure 7. PEE and COD removal performance when sodium hypochlorite was added in continuous running.

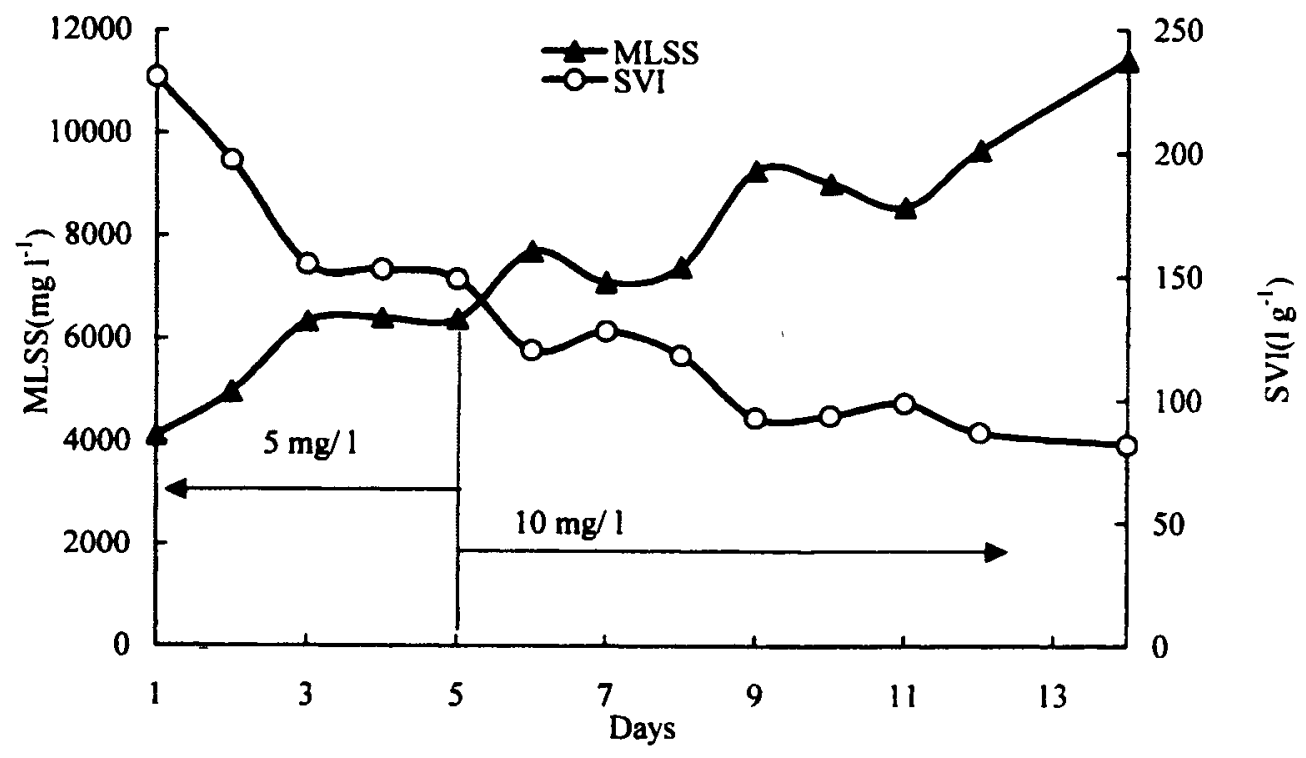

Figure 8. Variation of SVI and MLSS when sodium hypochlorite was added in continuous running.

reasonable dose. The side effects on $\mathrm{COD}$ and oil removals, however, were relatively high. The choice of addition of hypochlorite, therefore, should be considered seriously.

\section{CONCLUSION}

Yeast strains isolated from soil of a salad oil factory were investigated for salad oil wastewater treatment, and the stability of the yeast treatment system was investigated from several aspects. The following results were obtained:

- 5 kinds of yeast strains were obtained. The oil decomposition performance was comparable to the results of other researchers, although most of the strains were different.

- Sludge expansion accompanied with domination of true 
mycelia occurred during wastewater treatment. A mold, identified as Geotrichum candidum, was isolated from the expanded sludge. The mold seemed to be somehow related to sludge expansion.

- Sodium propionate was found to be effective for repression of sludge expansion. The dose, however, was as high as $0.3 \%$.

- $10 \mathrm{mg} \mathrm{l}^{-1}$ sodium hypochlorite was sufficient for decreasing SVI to 80 . The problem was that the activity of yeast was weakened at the same time.

- Further studies are needed to clarify the reasons of sludge expansion and to find an effective method for preventing or controlling sludge expansion.

\section{ACKNOWLEDGEMENTS}

The authors wish to acknowledge Mrs. Jia Jianhua, Institute of Microbiology. The Chinese Academy of Sciences, for her technical help in identification of strains. Thanks are also given to the committee of NSFC (National Science Foundation of China) for their support (No. 50078053).

\section{REFERENCES}

1. Ragazzi E. and Veronese G., The effect of oxidating coloration on the methanogenic toxicity and anaerobic biodegradability of phenols. Biol. Water, 32, 210-225 (1989).

2. Daniel S., Bailey's industrial oil and fat products. China Light-Industry Press, China (1979). (In Chinese)

3. Low, E. W. and Chase, H. A., Reducing production of excess biomass during wastewater treatment. Water Res., 33, 11191132 (1999).

4. Chigusa, K., Nishi, N., Matsumaru, M. and Minegishi, Y., Treatment of food manufacturing wastewater by yeast. J. Environ. Pollut. Contr., 25, 1557-1563 (1989). (In Japanese).

5. Kou, J.S., Kodama, T. and Minoda, T., Screening of yeasts and cultural conditions for cell production from palm oil. Agric. Biol. Chem., 47, 1207-1212 (1983).

6. Lie, E. and Persson, A., Screening of lipase-producing microorganism with a continuous cultivation system Appl. Microbiol., 35, 19-20 (1991).

7. Nawamura, Y., Nishi, T. and Chigusa, K., Process for high load treatment of wastewater containing fish meal by yeast. $J$. Operation and Installation., 11, 99-104 (1992). (In Japanese)

8. Scioli, C., and Vollaro, L., The use of Yarrowia Lipolytica to reduce pollution in olive wastewaters. Water Res. 31, 2520-2524 (1997).

9. Chigusa, K., Hasegawa,T., Yamamoto,N. and Watanabe,Y., Treatment of wastewater from oil manufacturing plant by yeasts. Water Sci. Technol., 34, 51-58 (1996).

10. Kreger-van Rij, N. J.W., The yeasts: a taxonomic study, (3 ${ }^{\text {rd }}$ ed.) Elsevier Science Publishers B.V., Amsterdam (1984).

11. Committee of State Environmental Protection Agency. Water and wastewater monitoring and analysis, 3rd edition. China Construction Industry Press, China (In Chinese) (1998). 